\title{
A cohesive FE model for simulating the cracking/debonding pattern of composite NSC-HPFRC/UHPFRC members
}

\author{
V. Savino ${ }^{\mathrm{a}}$, L. Lanzoni ${ }^{\mathrm{b}}$, A.M. Tarantino ${ }^{\mathrm{b}}$, M. Viviani $^{\mathrm{a}}$ \\ ${ }^{a} H E S-S O$ / HEIG-VD - Haute Ecole d'Ingénierie et de Gestion du Canton de Vaud, \\ Route de Cheseaux 1, CH-1401 Yverdon-les-Bains, Switzerland \\ ${ }^{b}$ DIEF-Department of Engineering "Enzo Ferrari", University of Modena and Reggio \\ Emilia, 41125 Modena, Italy
}

\begin{abstract}
The aim of this work is to propose to practitioners a simple cohesive FiniteElement model able to simulate the cracking/debonding pattern of retrofitted concrete elements, in particular Normal-Strength-Concrete members (slabs, bridge decks, pavements) rehabilitated by applying a layer of High-Performance or Ultra-High-Performance Fiber-Reinforced-Concrete as overlay. The interface was modeled with a proper nonlinear cohesive law which couples mode I (tension-crack) with mode II (shear-slip) behaviors. The input parameters of the FE simulation were provided by a new bond test which reproduces a realistic condition of cracking/debonding pattern. The FE simulations were accomplished by varying the overlay materials and the moisture levels of the substrate surface prior to overlay, since findings about their influence on the bond performances are still controversial. The proposed FE model proved to effectively predict the bond failure of composite NSC-HPFRC/UHPFRC members.
\end{abstract}

Keywords: composite structures; UHPFRC layer; debonding damage; numerical modeling; bond tests; peeling stress; shear stress; contact problem

Email address: luca.lanzoni@unimo.it (L. Lanzoni) 


\section{Introduction}

\subsection{The technology of the overlay materials : HPFRC and UHPFRC}

Advanced cement-based materials and emerging techniques for the design and protection of existing concrete members have been developed in the last decades. Relevant is the growing number of applications of High Performance-Fiber-Reinforced Concrete (HPFRC) on damaged concrete members [16, 32] $]^{1}$. Very interesting is also the recent application of Ultra-High Performance-Fiber-Reinforced Concrete (UHPFRC ${ }^{2}$ ) in pilot projects, e.g. rehabilitation of bridge deck overlays [13, 27] and reinforcement of hydraulic structures [25, 43]. The mechanical performances of UHPFRC are superior than those of ordinary and high-performance concretes. Beside its higher strength, low permeability and high energy absorption [13], UHPFRC has also shown high bond strength and good adherence to substrate made of normal-strength concrete (NSC) [1, 29, 54]. A large experimental investigation on the behavior of structures rehabilitated with UHPFRC revealed that such a material enhances the structural performances of composite members. However, the works in [1, 13, 42, 59] confirmed that the structural resistance of the composite material NSC-UHPFRC strongly depends on the bonding conditions.

\subsection{The bond performances : the risk of cracking/debonding failures}

A key issue of retrofitted concrete members concerns the risk of premature deterioration in the bonding region. This phenomenon is often observed in the practice after a period of service. According to the investigations above mentioned, the application of HPFRC and UHPFRC as overlay might reduce such a risk, if precautionary measures are taken into account. In the field of the retrofitted concrete structures the term interface relies on the penetration and hardening of the overlay inside the open cavities at the surface of the concrete substrate, resulting in a physical anchorage [8]. Two main factors can deteriorate such adhesion: the different volume changes between overlay and substrate and the effects of the external mechanical loading applied on the composite. For both cases, it is possible to distinguish different patterns of failure: i) the peeling stress perpendicular to the interface exceeds the

\footnotetext{
${ }^{1}$ Recent studies about damage in the framework of finite elasticity can be found in 36, 37, 38, 53 .

${ }^{2}$ whose mechanical performances are better than HPFRCs [15, 48, 49, 50]
} 

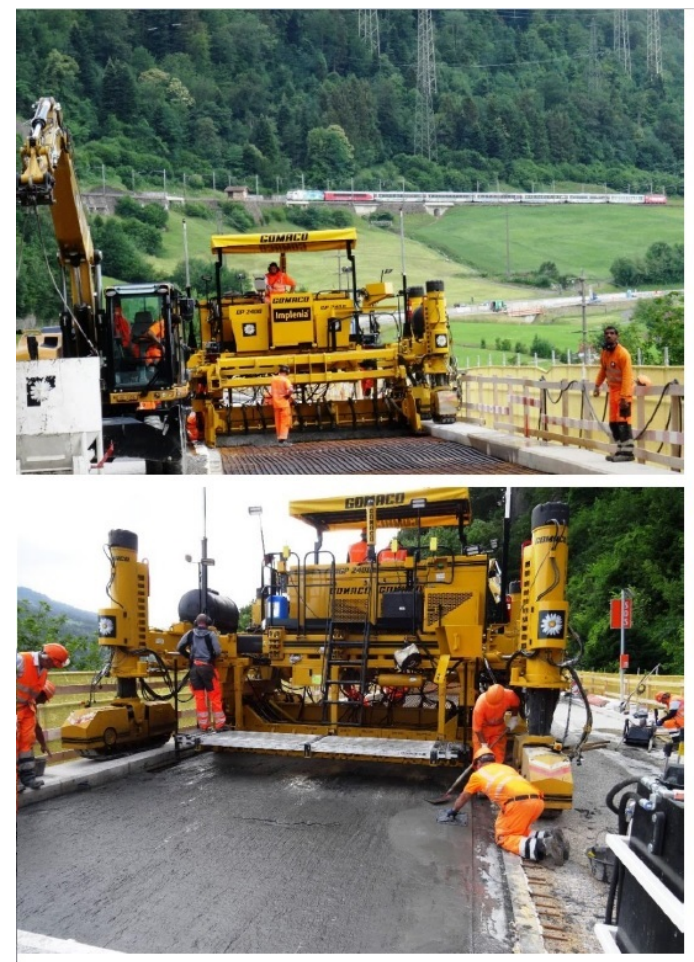

tensile strength, which causes crack opening (mode I); ii) the shear stress along the interface exceeds the respective strength, which causes slip (mode II); iii) a mix of mode I and mode II [24]. The latter is usual in retrofitted concrete members, such as slabs, bridge decks and pavements, see Fig. 1.

Figure 1: Switzerland 2018 [12 - Retrofitting of a bridge deck member by using a commercial UHPFRC

These composite structures are frequently stressed to bending loads. Near to zones of maximum negative moment the bending load induces a high stress at the interface of mode I which, detrimentally, adds its effects to mode II. If in these zones, there exist some discontinuities of the overlay, e.g. boundary locations, joints or cracks, the cracking/debonding failure might occur [23 (Fig. 2). In such conditions the bond failure is governed by a mutual interaction between mode I and mode II [24]. Current bond tests can assess the bond performances subjected to solely mode I (Pulloff test) or to a given combination of mode I and mode II (Slant/shear test). The latter, according several authors, may not be so representative since unrealistic loading conditions are applied at the interface [17]. Few research have focused on 

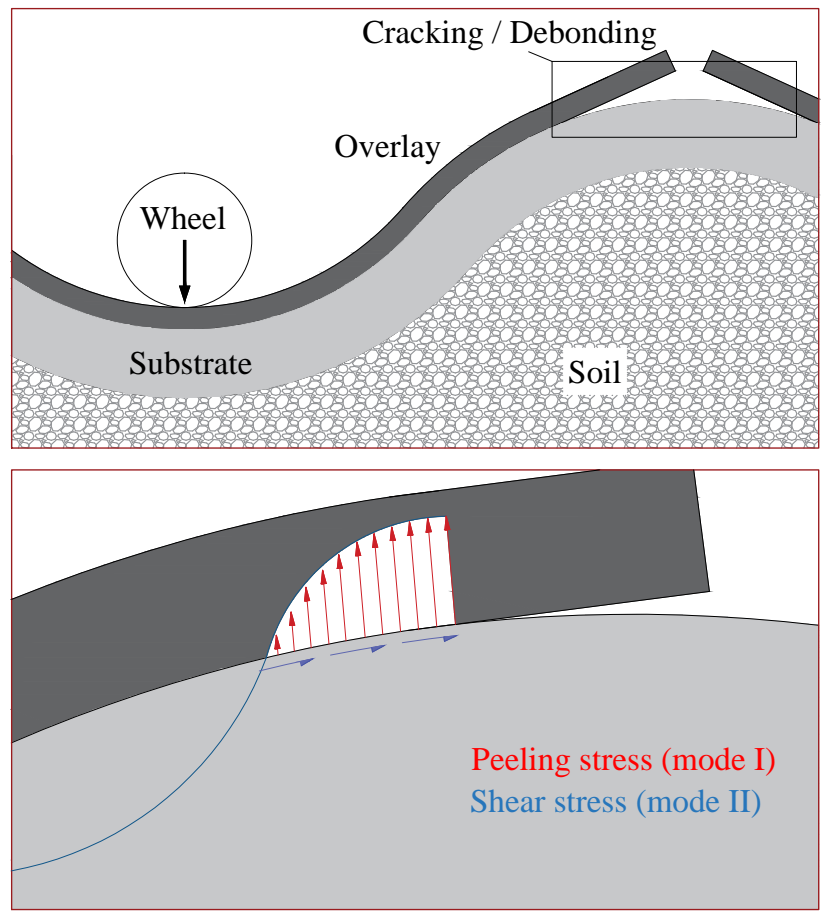

Figure 2: Illustration reported in [23] of a cracking/debonding path along the interface due to loading conditions on concrete pavements repaired by a layer of cement-based overlay

a finely prediction of the realistic mixed mode pattern, by coupling pulloff and slant/shear tests and adopting some empirical bond failure envelopes such as the Griffith theory and the Mohr-Coulomb criterion. Despite the efforts carried out by these authors, attempts according to the Griffith theory have proved unsuccessful, while the Mohr-Coulomb criterion is concerned with stress states within a material rather than at the interface between two bonded together [2]. In conclusion, by adopting current bond tests the risk to overestimate the bond performances is high, since they cannot reproduce a realistic conditions of cracking/debonding failure. Experimental evidences have also confirmed that the bond performances are sensitive to the substrate preparation prior to overlay. Recent works pointed out that the type of the overlay used and the moisture condition of the concrete substrate surface at the time of application of the overlay strongly affect the development of the bond strength. Certain authors stated that a dry substrate condition prior to overlay leads to better performances of the bond than saturated-surfacedry (SSD) conditions; in certain cases, SSD treatment was even detrimental 
[6, 57]. Different observations were presented in [40, 56], claiming that SSD condition improved the bond strength. Other authors suggested that the optimal saturation level ranges from 55 to $90 \%$ [9. It can therefore be concluded that these findings confirm that such a phenomenon is still controversial and further investigations are needed.

\subsection{Numerical investigations (FE simulation)}

It is well known that the interaction between the composite concrete members represents a relevant challenge in a numerical modeling, due to the complicated nature of their adhesion [52]. Concerning studies have been very limited in the past. The investigation of [1] and [45] predicted the behavior of composite NSC-UHPFRC members using a 3D FE analysis under the assumption of a perfect bond at the NSC-UHPC interface. This assumption increases the risk to overestimate the ultimate capacity of the composite structure. Other authors like 33 modeled the interface of a composite NSCUHPFRC member but no experimental data were available for validate their model. Even though the efforts accomplished in the above-mentioned works have been shown relevant outcomes, a calibration of the FE data on the basis of the experimental results was missing, or experimental investigations were carried out without any numerical simulations. Recently, some works proposed FE models calibrated on the basis of the experimental data. It is interesting to note that different approaches for modeling the interface were proposed in these works. [60] proposed equivalent beam elements to represent the bond behavior at the interface, instead [21] proposed to construct an interface material between the concrete layers used. Both models proved to be efficient and were validated by comparing their results with a three-point flexural test. It is important to note that these models reduce the overestimation of the bond performances as compared to "tie" models, in particular when either no surface preparation or no bonding agent are employed in certain cases [11, 21]. Despite their good efficiency the aforementioned models are complex and risk to reduce the practical interest of the practitioner which tends to simplify its numerical simulations by using "tie" interface conditions [31, 47]. However, with this assumption, the behavior of the interface cannot be directly observed when the cracking/debonding failure begins, so the risk to overestimate the bond performances increases. Furthermore their calibration should be done on the basis of realistic experimental tests [19, 20]. 


\section{Scope}

This paper presents a simple cohesive FE model able to simulate the cracking/debonding failure of retrofitted concrete structures, in particular a NSC member (e.g. slabs, bridge decks, pavements, etc.) rehabilitated by applying a layer of HPFRC or UHPFRC as overlay. The interface has been modeled with a series of vertical and horizontal truss elements which permits to predict the bond loading capacity and the propagation of the cracking/debonding path along the interface, on the basis of the energy balance concept of the fracture mechanism [44]. The mechanical response of the truss elements is provided by a nonlinear cohesive law which couples mode I (tension-crack) with mode II (shear-slip) behaviors. The nonlinear cohesive law has been defined on the basis of the experimental data provided by a new bond test designed by authors. The advantage of this test, compared to the current ones, is to reproduce a realistic cracking/debonding failure of the composite members, preventing the risk to overestimate the bond performances. Different overlay materials and moisture levels of the substrate surface prior to overlay are also taken into account, since findings about their influence on the bond performances are still controversial.

The present work is organized as follows: a description about the experimental campaign carried out for calibrating the input parameters of the cohesive FE model is provided in Section 3, in Section 4 the cohesive FE model is presented; in Section 5 the FE simulations are analysed and compared with the experimental results; the main conclusions are drawn in Section 6 .

\section{Experimental program}

In order to consider the effect of different environmental conditions, six slabs of substrate NSC 200x820x1140 mm were cast outdoors, both in summer and winter. 28 days later the slabs were demolded and exposed to external weather conditions ranging from $24{ }^{\circ} \mathrm{C}$ and $74 \% \mathrm{RH}$ in summer and $7{ }^{\circ} \mathrm{C}$ and $87 \% \mathrm{RH}$ in winter, for further 90 days. Then, the upper part of the NSC substrate (about $50 \mathrm{~mm}$ ) was removed by hydro-jetting. The roughness profile provided by the hydro-jetting was analyzed according to the photogrammetric method. In particular a commercial software Agisoft PhotoScan processed digital images and generates 3D spatial data of the scanned substrate surfaces. The processed data provide the roughness altitude in 4 points per square millimeters. Since the interface area of each 


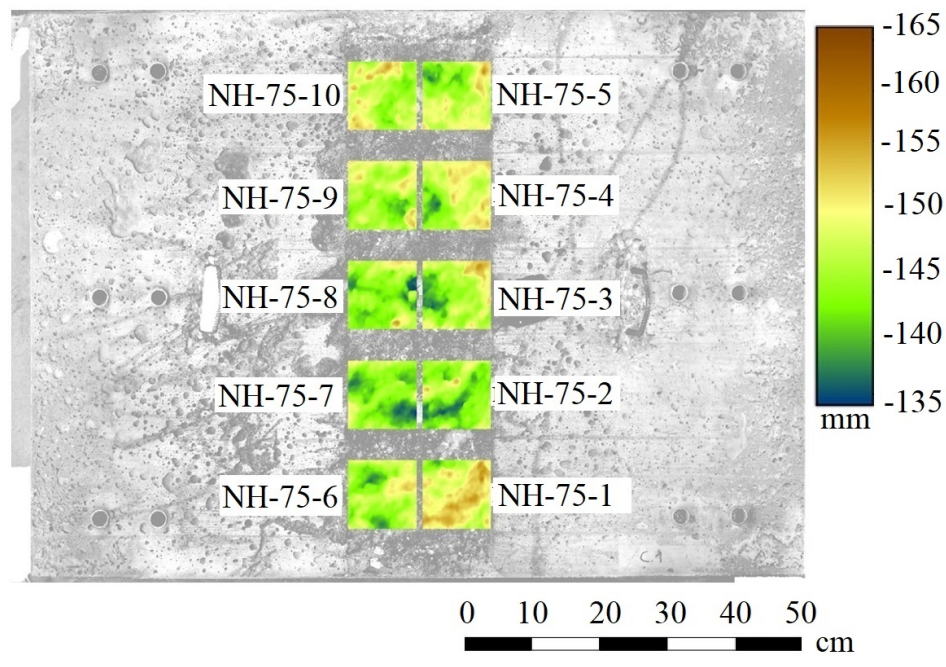

Figure 3: Roughness profile scanned for a given series (measuring in meters)

specimen was $100 \times 100 \mathrm{~mm}$, a population of 40000 points was used to calculate the average roughness and its standard deviation for each series. The analysis of the roughness magnitude was conducted for all series showing very similar values, as reported in Table 1. The colored area in Figure 3 represents the roughness profile of the substrate prior to the application of the overlay. Results agreed with the investigation of [41].

\begin{tabular}{ccccc}
\hline Interfacial zone & $\begin{array}{c}\text { Minimum } \\
(\mathrm{mm})\end{array}$ & $\begin{array}{c}\text { Maximum } \\
(\mathrm{mm})\end{array}$ & $\begin{array}{c}\text { Average } \\
(\mathrm{mm})\end{array}$ & $\begin{array}{c}\text { Stand. Dev. } \\
(\mathrm{mm})\end{array}$ \\
NH-75-_1 & 139.1 & 157.1 & 150.2 & 3.13 \\
NH-75-_2 & 135.7 & 154.0 & 143.6 & 3.16 \\
NH-75-_3 & 136.3 & 156.5 & 145.9 & 3.82 \\
NH-75-_4 & 136.4 & 155.0 & 147.2 & 3.90 \\
NH-75-_5 & 137.3 & 156.5 & 146.8 & 3.22 \\
NH-75-_6 & 136.9 & 153.6 & 145.7 & 3.19 \\
NH-75-_7 & 134.5 & 151.9 & 143.1 & 3.05 \\
NH-75-_8 & 135.2 & 156.0 & 144.3 & 3.17 \\
NH-75-_9 & 139.2 & 154.0 & 146.3 & 2.81 \\
NH-75-_10 & 141.2 & 155.6 & 147.4 & 2.89 \\
\hline
\end{tabular}

Table 1: Logged roughness profile for a given series

The substrate surface provided by hydro-jetting was properly cleaned and moistened according to different moisture levels prior to the application of 


\begin{tabular}{lcc}
\hline & $\mathrm{kg}$ in $1 \mathrm{~m}^{3}$ of composite \\
Compounds & HPFRC & UHPFRC \\
\hline Premix (cement, silica fume, sand) & 2135 & 1970 \\
Water & 230 & 195 \\
Superplasticizer & 21.3 & 39 \\
Hooked steel fibers $30 / 0.6 \mathrm{~mm}$ & $25(0.3 \%)$ & - \\
Straight steel fibers $13 / 0.175 \mathrm{~mm}$ & - & $296(3.8 \%)$ \\
\hline
\end{tabular}

Table 2: Material composition of the overlay

the overlay. Then, a commercial HPFRC was poured on three slabs, and a commercial UHPFRC ${ }^{3}$ was poured on the other ones. The material composition of the overlay are reported in Table 2 .

After 28 days of curing of the overlay the specimens were prepared for bond testing. The mechanical properties of the overlays used are reported in Table 4.

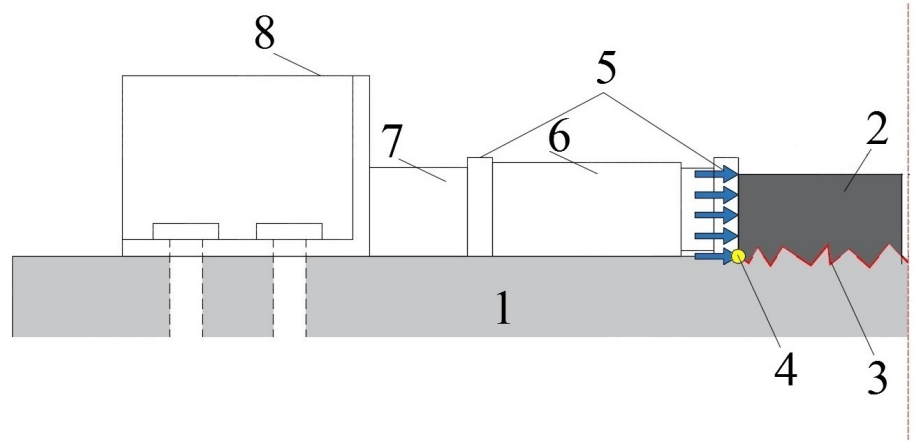

Figure 4: Bond test configuration designed by authors: (1) substrate, (2) overlay, (3) interface, (4) slip point measured by LDTV, (5) bearing plates, (6) loading device, (7) force transducer, (8) rigid support

The specimens were labeled according to both type of bonded materials, i.e. NH and NU stand for NSC-HPFRC and NSC-UHPFRC respectively, and the moisture levels of the substrate surface prior to overlay. The whole range of possible moisture conditions expected in the field was taken into account in series investigated, in particular dry, 75\% and SSD. Dry-type surface was reached by curing the substrate surface for 14 days at laboratory

\footnotetext{
${ }^{3}$ previously investigated in 48
} 
conditions of $23 \pm 2^{\circ} \mathrm{C}, 55 \% \pm 5 \% \mathrm{RH}$, as also seen in [3]. During the curing, surface substrate was covered with a plastic sheet, in order to slow down the carbonation process. $75 \%$ and SSD conditions were achieved by keeping wet the substrate surface for 24 hours, then surface was manually dried with towels to attain the SSD conditions. Several hours later, at laboratory conditions, a moisture level of $75 \%$ was reached. The surface moisture level was measured by a superficially encased relative humidity probe, in particular a ROTRONIC type HC2-AW. The digital probe signal is processed by a Hygro Palm 23 multifunction hand-held indicator. It provides temperature, $\mathrm{RH}$ and time of measure. In order to detect the cracking/debonding failure observed in field, a proper bond test, was designed by the authors. In [51], Silfwerbrand J. presented various test methods used to evaluate the bond strength at the interface. Among them, pull-off and slant/shear tests were also adopted in standards ASTM [61] and 62, respectively. Even though in [51] Silfwerbrand J. mainly presented a torsional bond test method, he also provided an overview about the lateral shear bond test method. The authors attempted to find regulations and other works containing further details of such a test method, but with poor results. However, lateral shear test was adopted in this investigation since it can reproduce the realistic condition of mixed mode expected in the field [23], see Fig. 2. An external load, parallel to the interface, is applied to the overlay edge. The load transmits the shear stresses along the interface (mode II). A peeling stress (mode I) arises on the interface as soon as the shear load is applied, due to the eccentricity of the shear load from the interface. A couple of LDTVs are placed on both sides of the specimen for measuring the average slip/debonding at the point of load application, see Fig. 4. The loading rate is very low $(0.003 \pm 0.002 \mathrm{MPa} / \mathrm{s})$ in order to properly detect the interfacial bond response [10].

\section{Modeling of composite NSC-HPFRC/UHPFRC members}

\subsection{The code Strandry}

The commercial software package Strand7 ([4, 14, 22, 26, 46]) was adopted for simulating a realistic case of cracking/debonding failure (Fig. 2) between a NSC substrate and a cement-based overlay. The code provides a series of tools and functions for obtaining the approximate solution of the problem investigated, according to the steps listed below:

1. Defining the geometric and loading characteristics of the retrofitted composite member; 
2. Defining the material characteristics of the bonded materials (constitutive equations);

3. Dividing the physical system into elements and nodes (meshing of both the single materials and the interface);

4. Forming the element matrices (stiffness, mass and damping elements) and vectors (nodal load and restraint elements);

5. Assembling the element matrices into global matrices and the element vectors into global vectors;

6. Solving the global equilibrium equations for the primary unknown variables and generating element results (i.e. kinematic and stress field at the interface);

7. Generating other useful result data such as transformation and extrapolation of results;

8. Investigating and interpreting the result data.

Step 1 to 3 are performed with the pre-processor; step 4 to 6 are performed with the solver; step 7 to 8 are performed with the post-processor. The approximated solution considers the three physical laws of the continuum mechanic. The equilibrium equation system, which is formulated on the basis of the principle of virtual work, is a direct result of considering force equilibrium and displacement compatibility at the nodes. The global equations are solved by direct or indirect methods. The direct method uses the Crour's algorithm to decompose the global matrices into a triangular form. Instead, the indirect method uses the Pre-conditioned Conjugate Gradient algorithm [55]. The solutions yield one or more vectors of nodal displacements which are used to determine element stress and strain and nodal reactions in the structural solution.

\subsection{Modeling of the interface}

In the composite concrete members the link layer between the substrate and the overlay is usually composed by a porous media thin layer of 100 $\mu \mathrm{m}$ consisting of weak hydrates such as calcium hydroxide [6] and plays a key role in the bond strength [7, 18, 58]. In addition, the high roughness profile provided by common removal methods of the deteriorated concrete, like hydro-jetting, increases the bond performances thanks to the interlocking mechanism provided by the hydro-jetting [5]. This aspect is considered into the model presented in the following. In Strand7, when two surfaces are bonded a fictitious layer of zero thickness exists between these. The contact 
condition/effect to be physically modeled requires that the interface provides infinite stiffness so that the two surfaces cannot go penetrate each other. The deformations around the interface area occur within the material on both side of the interface [55]. For this purpose, the interface is modeled by so-called master-slave elements. This kind of link, which is a module given by the code, is not a real element like beam or plate. The master-slave link provides the physical condition discussed above, by defining relationships between two nodes so that the displacement of the selected components will be of the same magnitude. Conceptually, a master-slave link will enforce the slave node to follow the master node in the selected displacement directions, either in the global coordinate system or in any user coordinate system, see Fig. 5. Although the link is referred to as a master-slave link, there is no real distinction as to which node is the master and which node is the slave. For example, a master-slave link connecting node 1 to node 40 is identical to one connecting nodes 40 and 1. During a processing, the solver will enforce the condition that the two nodes have same displacement values for the selected components. In the model, a smooth geometrical interface is assumed, since the effect of the roughness profile on the bond strength can be taken into account by properly calibrating the stiffness of the master-slave links. The stiffness of the the master-slave link, in regard with the relative displacements of its facing nodes (opening crack $v$ and slip $u$ ), is calibrated by pin-connecting the master-slave link to truss elements. In the code, a truss element is a straight element pin-connected at its joints, which carries only tensile and compressive forces along its axial direction. In a truss element all loads can be applied to its joints and not between them. The mechanical behavior of the truss elements was properly calibrated on the basis of the experimental data, in order to simulate the peeling mode (I) and the shear mode (II) responses at the interface. For this purpose, a nonlinear cohesive law was adopted. The thickness FE interface layer was assumed to be 100 $\mu \mathrm{m}$ length, in agreement with [6]. An illustration is reported in Fig. 5.

The nonlinear cohesive law above mentioned can be defined into the code by selecting the function Stress vs Strain Table. In this table it is possible to calibrate the mode I and mode II relationships that will govern the mechanical response of the $100 \mu \mathrm{m}$-vertical and $1000 \mu \mathrm{m}$-horizontal truss elements, respectively. This technique permits to directly calibrate the nonlinear response of the interface face to peeling and shear stresses induced by the external load, until the peak of bond strength is reached. Then, the propagation of cracking/debonding begins and the frictional effect ensures a 


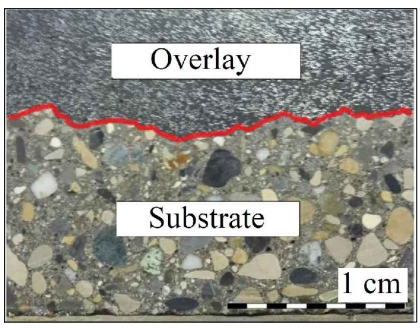

a)

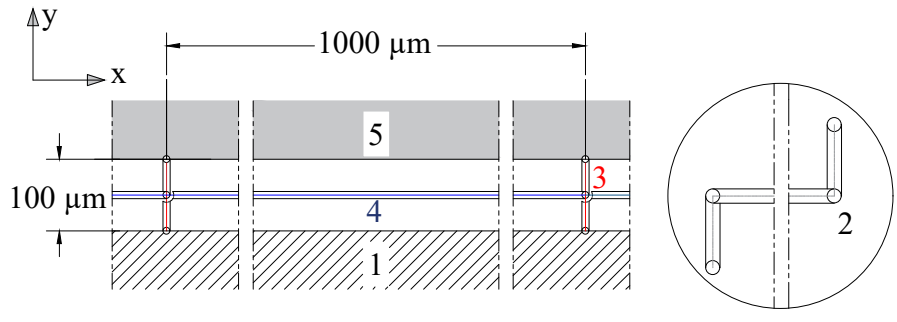

b)

Figure 5: a) Interface profile observed by cutting the retrofitted member; b) Modeling of the interface between the substrate (MIR) (1) and the overlay (1-mm mesh) (5). The contact-condition effect between the two materials is modeled by using master-slave elements (2). The peeling-opening (mode I) and the shear-slip (mode II) relationships at the interface are modeled by using $100 \mu \mathrm{m}$-vertical (3) and $1000 \mu \mathrm{m}$-horizontal (4) truss elements, respectively

residual bond strength prior to reach the complete failure [24, 30, 47]. This important phenomenon cannot be directly accounted by nonlinear cohesive laws governing tied nodes. However, the residual strength provided by the frictional effect can be taken into account according to the energy balance concept of the fracture mechanism. While the cracking/debonding path increases, the peak of bond strength is kept constant in the truss elements, until the value of energy absorbed by the overall FE interface attains the value of the maximum energy absorbed by the real interface, prior to the complete failure. This approach requests, of course, several iterations for properly calibrating the cohesive law on the basis of the experimental test data, which are presented in Section 3. The construction of such a law into the code is illustrated in Fig. 6. The branches b-c in Fig. 6a and a-b/e-f in Fig. 6b correspond to the plateau of strength discussed above, which is reached when the propagation of cracking/debonding begins.

In the first iteration, the mode I and mode II relationships were calibrated on the basis of the results presented in 24. As mentioned above, the final expressions of the cohesive law are fitted through an iterative process, until the simulated load - slip/debonding curve agrees with the experimental one presented in Section 3. The FE parameters of the nonlinear cohesive law showed in Fig. 6 are reported in Table 3, for all series investigated. In order to consider the fact that the flexural deformation of the overlay produces a compressive stress along certain regions of the interface, a compressive-strain 

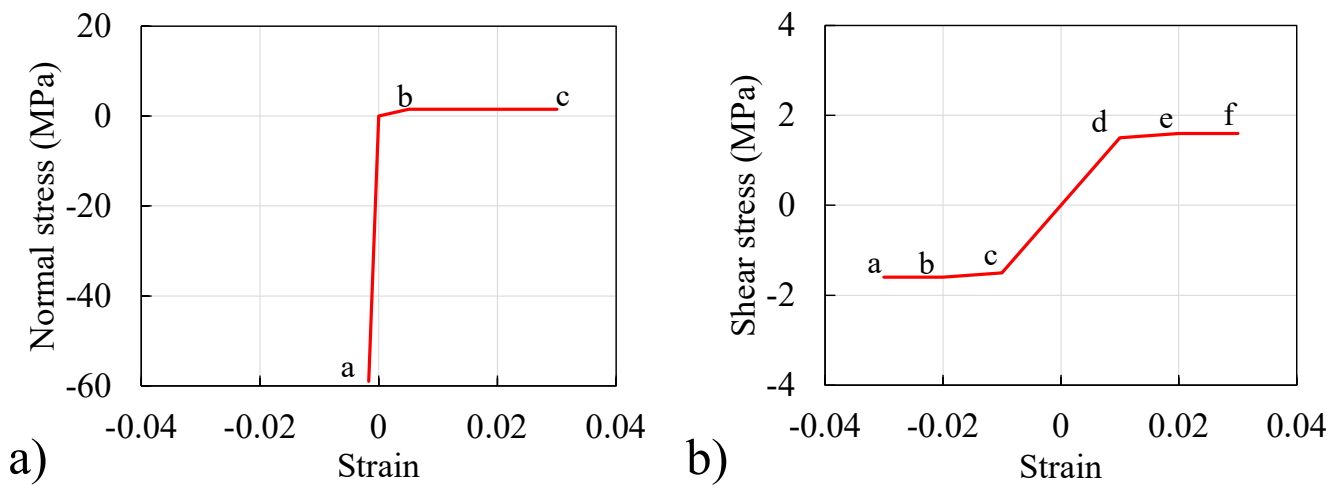

Figure 6: Strand7 environment. Series NH-dry: The function stress vs strain permits to construct the nonlinear cohesive law governing the interface response subjected to normal (a) and shear (b) stresses. In each figure, the points in which the slope of the function stress vs strain changes are labeled according to letter a, b, c, etc.

law was implemented (see the branch a-0 in Fig. 6a). In this law the peak point corresponds to the compressive strength of the weaker material between the substrate and overlay, i.e. the NSC substrate. The corresponding strain is derived as the ratio between the compressive strength and the elastic modulus in compression, both experimentally measured, see Table 4. For both signs of slipping (left towards or right towards) the horizontal truss response does not change in terms of absolute value, so $\tau(a)=-\tau(f), \tau(b)=-\tau(e)$ and $\tau(c)$ $=-\tau(d)$.

\begin{tabular}{|c|c|c|c|c|c|c|c|c|c|c|c|c|}
\hline \multirow{3}{*}{ Series } & \multicolumn{6}{|c|}{ Vertical truss } & \multicolumn{6}{|c|}{ Horizontal truss } \\
\hline & $\mathrm{v}(\mathrm{a})$ & $v(b)$ & $\mathrm{v}(\mathrm{c})$ & $\sigma(a)$ & $\sigma(b)$ & $\sigma(c)$ & $\mathrm{u}(\mathrm{a})$ & $\mathrm{u}(\mathrm{b})$ & $\mathrm{u}(\mathrm{c})$ & $\tau(a)$ & $\tau(b)$ & $\tau(c)$ \\
\hline & \multicolumn{3}{|c|}{$\mathrm{mm} / \mathrm{mm}$} & \multicolumn{3}{|c|}{$\mathrm{MPa}$} & \multicolumn{3}{|c|}{$\mathrm{mm} / \mathrm{mm}$} & \multicolumn{3}{|c|}{$\mathrm{MPa}$} \\
\hline NH-dry & -0.00169 & 0.005 & 0.03 & -59 & 1.5 & 1.5 & -0.03 & -0.02 & -0.01 & -1.8 & -1.8 & -1.7 \\
\hline NH-75 & -0.00169 & 0.005 & 0.03 & -59 & 1.2 & 1.2 & -0.03 & -0.02 & -0.01 & -2 & -2 & -1.2 \\
\hline NH-SSD & -0.00169 & 0.005 & 0.03 & -59 & 1.6 & 1.6 & -0.03 & -0.025 & -0.01 & -2.3 & -2.3 & -1.1 \\
\hline NU-dry & -0 & 0.005 & 0.03 & -59 & 1.7 & 1.7 & -0.03 & -0.02 & -0.01 & -2.8 & -2.8 & -1.8 \\
\hline NU-75 & -0.00169 & 0.005 & 0.03 & -59 & 2.1 & 2.1 & -0.03 & -0.025 & -0.01 & -3.1 & -3.1 & -1.4 \\
\hline NU-SSD & -0.00169 & 0.005 & 0.03 & -59 & 3 & 3 & -0.03 & -0.02 & -0.01 & -4.5 & -4.5 & -3.4 \\
\hline
\end{tabular}

NH: NSC bonded with HPFRC.

NU: NSC bonded with UHPFRC.

dry: dry substrate prior to be overlaid.

75: substrate moisture level of $75 \%$ prior to be overlaid.

SSD: substrate saturated-surface-dry prior to be overlaid.

Table 3: Interface: FE parameters 


\subsection{Modeling of the single-materials (substrate and overlay)}

Besides the bonding properties, further properties that also affect the contact problems include the elastic modulus, the shear modulus, the Poisson's ratio and the geometry of both bonded materials [35]. On the basis of the experimental data obtained from single-material tests, such properties were implemented into the FE code, see Table 4 . It is worth mentioning that tests on single-materials are independent of the bonding properties of the bonded members.

\begin{tabular}{|c|c|c|c|c|c|c|c|c|c|}
\hline \multirow[b]{2}{*}{ Series } & \multicolumn{6}{|c|}{ Overlay } & \multicolumn{3}{|c|}{ Substrate } \\
\hline & $\mathrm{b}$ & 1 & $\mathrm{~h}$ & $\mathrm{E}$ & $\nu$ & $f_{c}$ & $\mathrm{~h}$ & $\begin{array}{l}\text { Modeled } \\
\text { as }\end{array}$ & $f_{c}$ \\
\hline & $\mathrm{mm}$ & $\mathrm{mm}$ & $\mathrm{mm}$ & GPa & adim. & $\mathrm{MPa}$ & $\mathrm{mm}$ & & $\mathrm{MPa}$ \\
\hline NH-dry & 100 & 100 & 50 & 38.3 & 0.17 & 78 & 200 & MIR & 59 \\
\hline NH-75 & 100 & 100 & 50 & 38.3 & 0.17 & 78 & 200 & MIR & 59 \\
\hline NH-SSD & 100 & 100 & 50 & 38.3 & 0.17 & 78 & 200 & MIR & 59 \\
\hline NU-dry & 100 & 100 & 50 & 47.1 & 0.2 & 147 & 200 & MIR & 59 \\
\hline NU-75 & 100 & 100 & 50 & 47.1 & 0.2 & 147 & 200 & MIR & 59 \\
\hline NU-SSD & 100 & 100 & 50 & 47.1 & 0.2 & 147 & 200 & MIR & 59 \\
\hline
\end{tabular}

b: width of the overlay.

l: length of the overlay.

h: thick of the overlay/substrate.

E: Elastic modulus measured according to the 63 .

$\nu$ : Poisson's ratio for HPFRC and UHPFRC estimated according to [39] and 28], respectively $f_{c}$ : Compressive cubic strength measured according to the 64 MIR: Modeling of the substrate as a member infinitely rigid.

Table 4: Bonded materials: FE parameters

The elastic modulus $E$ of the substrate is assumed to be $25700 \mathrm{MPa}$, according to the formulation reported in [65]. The surface area $A_{\text {sub }}$ of the substrate and of the overlay $A_{\text {overl }}$ along the vertical plane is $200 \times 820 \mathrm{~mm}$ and $50 \times 100 \mathrm{~mm}$, respectively. Thus, the elastic and the surface ratios $A_{\text {overl }} / A_{\text {sub }}$ between the overlay and substrate are about 1.6 and 0.03 , respectively. The resulting stiffness ratio $E A_{\text {overlay }} / E A_{\text {substrate }}$ is about 0.045 . Consequently, the substrate can be modeled as a member infinitely rigid (MIR).

In order to consider the non-linear response of the contact problem, a non linear static analysis was carried out. In Strand7, the nonlinear static solver 
uses an algorithm based on the modified Newton-Raphson method to solve the nonlinear equation system. The algorithm uses an iteration procedure within each load increment to ensure that the equilibrium of forces is maintained, within a specified allowance, at the end of each load increment. An incremental displacement history was assigned to the end side of the overlay in order to simulate the cracking/debonding failure at the interface. Each increment of displacement $u$, corresponding to the step 1, step 2, etc. of the analysis, was small enough $(0.0005 \mathrm{~mm})$ to make the nonlinear analysis efficient. It is worth noting that the resulting stress field was uniformly distributed along the width of the interface. This permitted to further simplify the numerical calculations, by selecting the function of 2-D stress plane and modeling the layer of the overlay as a group of plate $\left.\right|^{4}$ items.

In the field of FE models better solutions are given for meshes which have both a simple geometrical shape and a sides' ratio close to 1 [55]. A 4node quadrilateral type was therefore employed for modeling the mesh of the overlay. The mesh size of $1 \mathrm{~mm}$ was adopted, due to the fact that the independence of the calculation result versus the mesh size was reached when the node-to-node distance was $\leq 1 \mathrm{~mm}$. The overlay size was of course defined in respect to the size of the experimental specimen, see Table 4

\section{FE simulations and Results}

As discussed in Section 4 a nonlinear static analysis was adopted for stressing the interface to mixed mode, by increasing step by step the displacement assigned to the end side of the overlay specimen, see Fig. 7. For each increase of displacement the stress field arising on the modeled interface was analyzed. In each step, the integration of the internal shear stress along the modeled interface (Fig. 8b) must be equal to the experimental load $F_{x}$ applied to the end side of the overlay specimen (Fig. 8k). Instead the integration of the internal stress perpendicular to the interface must be equal to zero in order to respect the vertical static equilibrium (Fig. 8a). The cohesive FE model permitted to observe the propagation of the cracking/debonding failure along the interface, as the external load increases. Fig. $8 \mathrm{~b}$ denotes that for small increases of displacement $(u<0.0075 \mathrm{~mm}$, from step 0 to step 100) the punctual shear stress along the interface increases by moving toward

\footnotetext{
${ }^{4}$ The plate item is a surface element with a given thickness.
} 
the edge side subjected to the external displacement $u$. This is due to the fact that the FE bonding response in mode II is still in elastic field : thus, the shear stress grows up as the slip magnitude increases, see Fig. 6b. For higher increases of displacement $(u>0.0075 \mathrm{~mm}$, from step 100 to step 300) the yield strength in mode II is reached, therefore a plastic FE bonding response is achieved, see Fig. 6b. As a result, the punctual shear stress becomes almost constant along the overall length of the interface and does not increase further, even though the slip/debonding keeps growing. The plastic behavior of the FE interface corresponds to the phenomenon of cracking/debonding which begins and quickly propagates along the real interface. This statement can be confirmed by observing the experimental curve in Fig. 8c. In particular, the slip value corresponding to the drop in force just after the peak load recorded in the experimental curves almost corresponds to the total propagation of the cracking/debonding path along the modeled interface. In addition, for all series, the experimental-to-numerical peak load ratio $F_{x, \exp }$ / $F_{x, F E M}$ showed good accuracy. Also the initial stiffness was accurately predicted.

\section{Step $1(\mathbf{u}=\mathbf{- 0 . 0 0 0 5} \mathbf{~ m m})$}

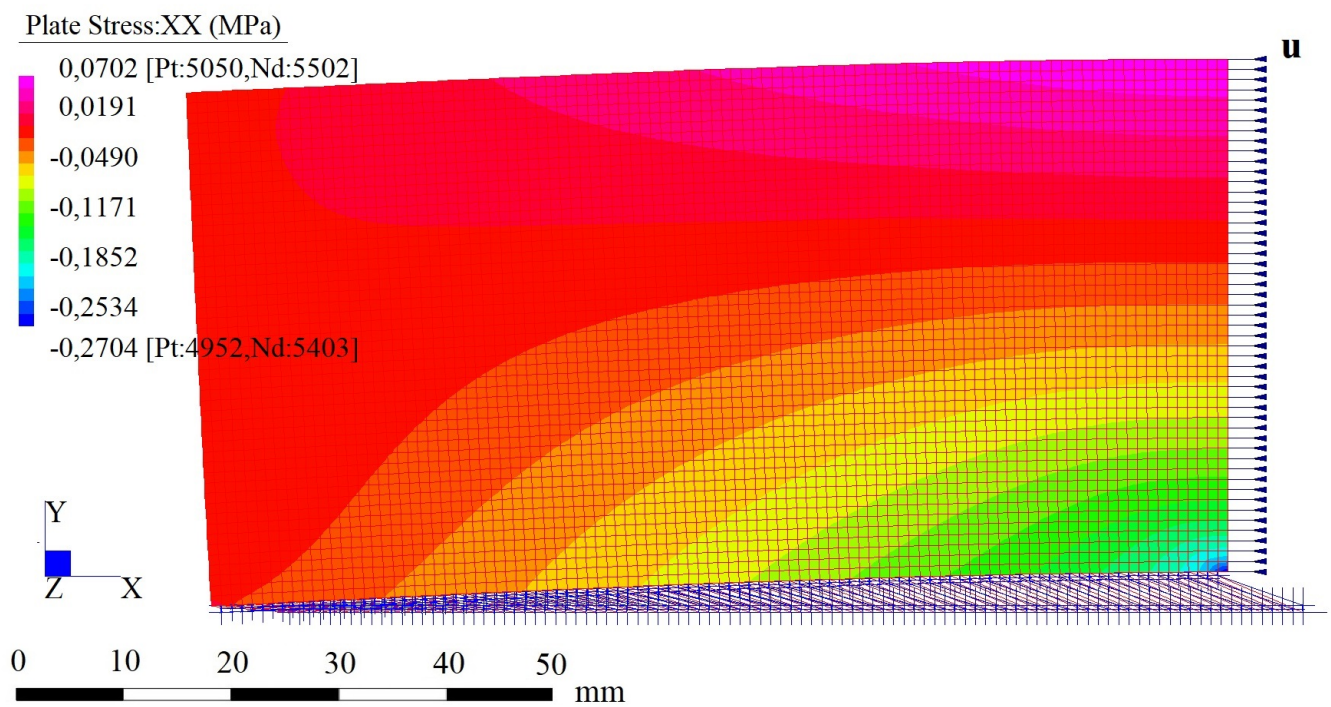

Figure 7: FE simulation of the cracking/debonding pattern of series NH-dry

Fig. 9 illustrates the cracking/debonding paths simulated on all series investigated, showing a good agreement with the experimental data. Each red 

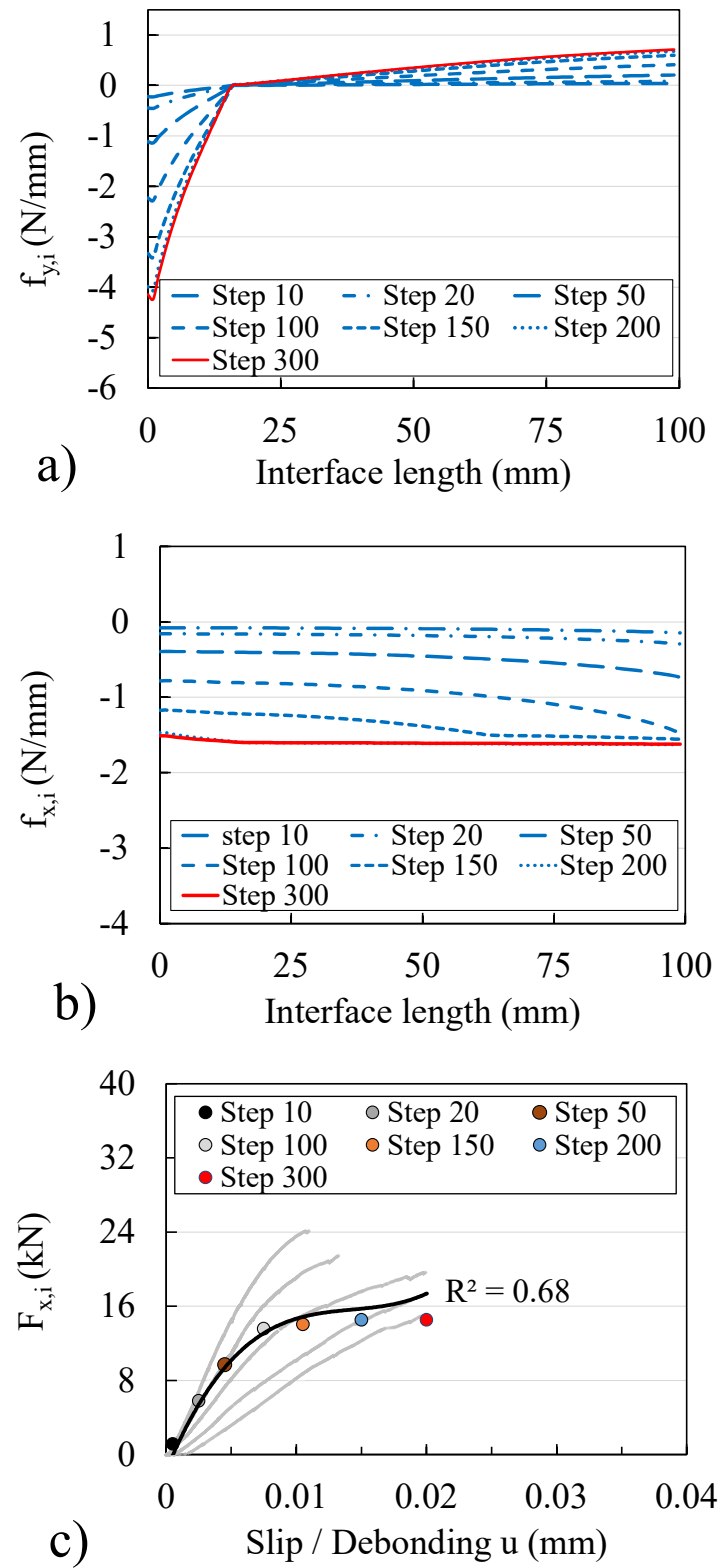

Figure 8: Analysis of the stress field on the modeled interface in series NH-dry recorded by the nonlinear static analysis: a) normal stress (mode I), b) shear stress (mode II). Load vs slip/debonding curve: c) simulation and experiment 

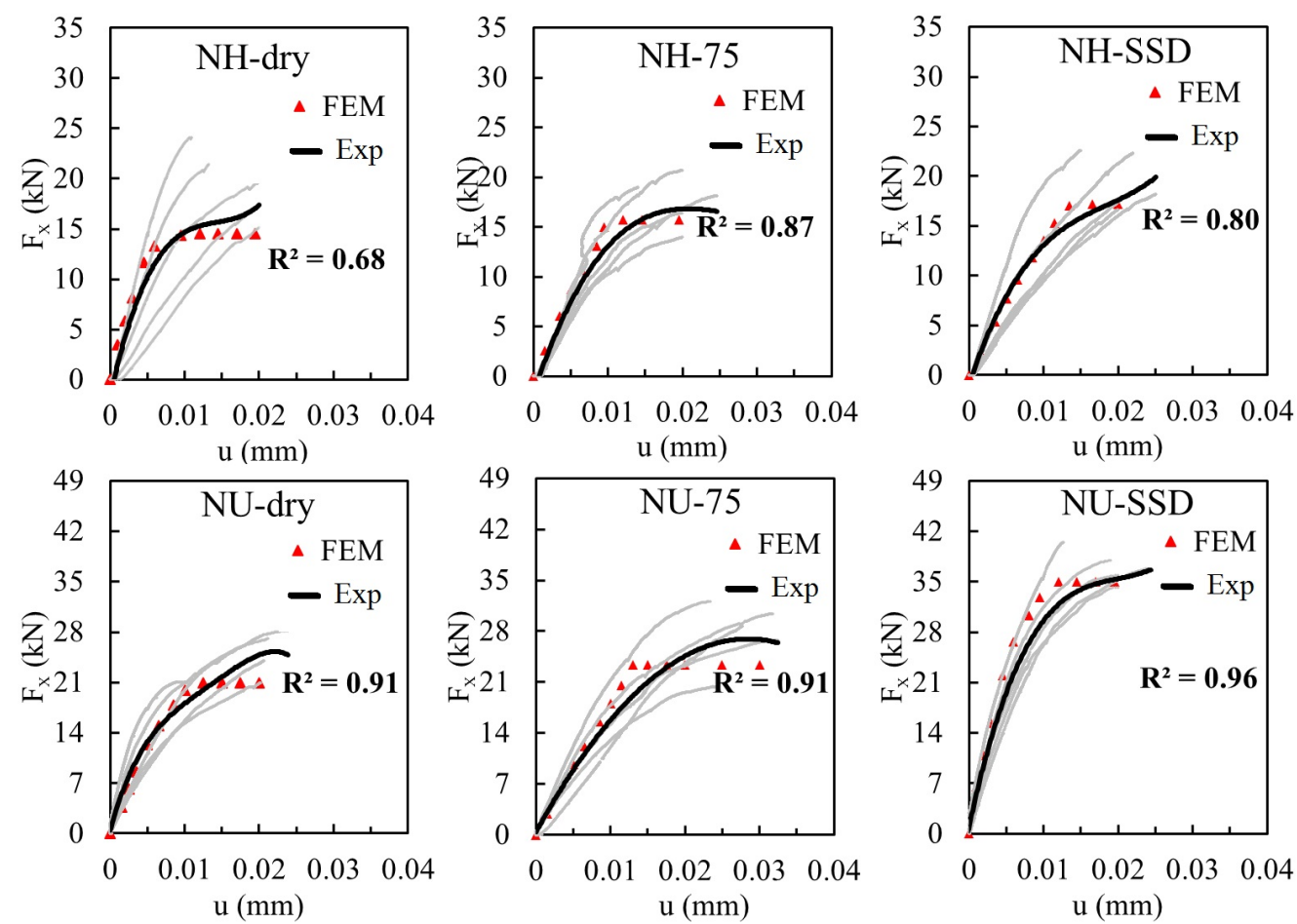

Figure 9: Numerical and experimental results of the model considering different conditions of type of overlay and moisture conditioning of the surface substrate prior to the application of the overlay

point in the figure represents the $F_{x, i}$ value corresponding to each increase of $u$ recorded by the experimental tests. In Figs. $8 \mathrm{c}$ and 9 the gray lines represent the experimental curves recorded for each tested specimen. Instead, the black curve represents the experimental average derived from a polynomial regression analysis of the experimental data. Such a curve is considered sufficiently representative because of its high $R^{2}$ value obtained. It can be noted that a lower scatter of experimental data was recorded in NU series ( $R^{2}$ ranging from 0.91 to 0.96 ), especially for high moisture levels. Conversely, higher scatter values were observed in NH series $\left(R^{2}\right.$ ranging from 0.68 to 0.80 ), in particular for low moisture levels. This difference was likely due to the fact that high moisture levels promote the hydration of the fresh overlay in the interfacial zone, leading to stronger bond between substrate and hardened overlay. This effect is magnified when a UHPFRC (NU series) is used as overlay. The absence of aggregate within UHPFRC mixture permits 


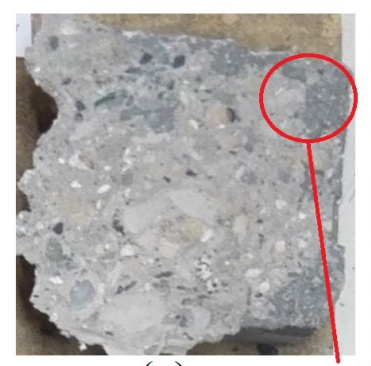

(a)

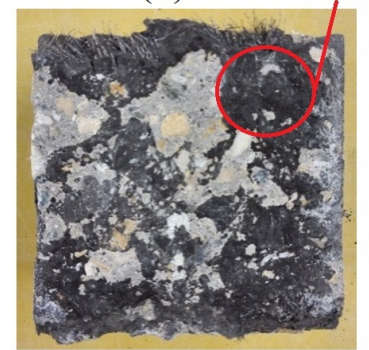

(d)

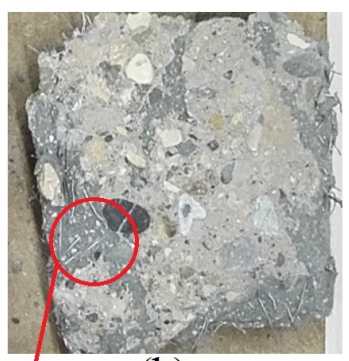

(b)

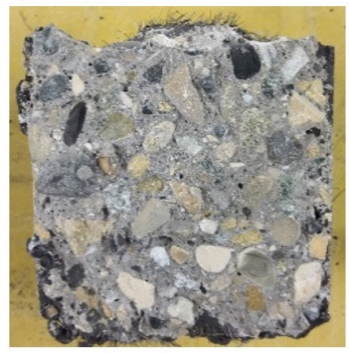

(e)

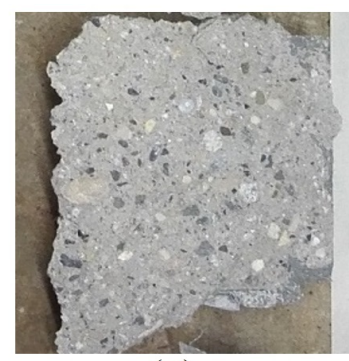

(c)

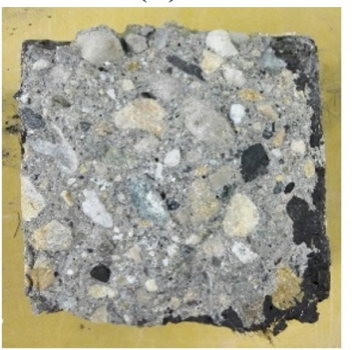

(f)

Figure 10: Surface failure observed after cracking/debonding of a) NH-dry, b) NH-75, c) NH-SSD, d) NU-dry, e) NU-75, f) NU-SSD

to extend the specific surface of adhesion between substrate and overlay, increasing the density of the interfacial zone. Both aspects reduce the defects along the interface and consequently explain the low scatter of results observed in NU series with high moisture levels as well, see Fig. 9.

The experimental results confirmed that lower moisture levels leads to lower bond strength values when UHPFRC is used as overlay. By contrast, when HPFRC is used as overlay the bond strength is almost the same under any moisture levels. Such a difference is probably due to the different w/c ratio between the two overlays investigated. The low w/c ratio of UHPFRC $(<0.2)$ makes this type of overlay highly sensitivity to the moisture level, especially under dry conditions. In such a condition an insufficient hydration of the fresh overlay in the interface zone occurred. This reduced the densification of the bond and its strength as well, showing a slight failure in the overlay, see Fig. 10. Instead, in the HPFRC series, the bond strength is less sensitive to the moisture level because of its higher $\mathrm{w} / \mathrm{c}$ ratio $(>0.2)$. Series investigated confirmed that the application of UHPFRC as overlay provides higher loading bond capacity to the composite structure, compared to the application of HPFRC. In particular, it was observed a bond strength ratio between the 
use of UHPFRC and HPFRC as overlay ranging from 1.13 to 2, see Table 4.

\section{Summary and Conclusions}

The cracking/debonding failure in composite NSC-HPFRC/UHPFRC members was simulated using the developed cohesive FE model with Strand7 software. The interface has been modeled with a series of vertical and horizontal truss elements which permitted to predict the bond loading capacity and the propagation of the cracking/debonding path along the interface, on the basis of the energy balance concept of the fracture mechanism. The mechanical response of the truss elements is provided by a nonlinear cohesive law which couples mode I (peeling) with mode II (slip). The FE parameters were finely calibrated on the basis of a bond test designed by the authors which reproduces a realistic condition of cracking/debonding failure. The main conclusions of this study can be drawn.

- The developed cohesive FE model yielded good predictions for the overall response of both the composite NSC-HPFRC and NSC -UHPFRC members subjected to mixed mode. In particular, the FE model predicted the stress field and the propagation process of cracking/debonding along the interface. These predictions are validated by the experimental load-slip/debonding test, in which the peak load and stiffness of the numerical curves agree with the experiment;

- The technique to characterize the interface adopting truss elements governed by a nonlinear cohesive law proved to be effective for simulating the cracking/debonding pattern of composite NSC-HPFRC/UHPFRC members. This technique adequately assessed the bond loading capacity, whose performances exhibited a clear susceptibility to both the type of the overlay used and the moisture level of the substrate prior to be overlaid;

- All bond tests have showed that the cracking/debonding failure occurred within the interface layer. For reproducing such a phenomenon the technique of the nonlinear cohesive law adopted in the FEM resulted appropriate, as confirmed by the numerical simulations;

- The presented FE model can be used for predicting the damage process at the interface of retrofitted structures like bridge decks, pavements 
and slabs, in which the mutual stress in tension and shear govern the failure pattern.

\section{Acknowledgments}

Authors gratefully acknowledge the financial support provided by HEIGVD. Financial support from the Italian Ministry of Education, University and Research (MIUR) in the framework of the Project PRIN "Modelling of constitutive laws for traditional and innovative building materials" (code 2017HFPKZY) is gratefully acknowledged.

\section{References}

[1] Al-Osta M, Isa M, Baluch M, Rahman M. Flexural behavior of reinforced concrete beams strengthened with ultra-high performance fiber reinforced concrete. Construction and Building Materials 134, 2017, pp. 279-296.

[2] Austin S, Robins P, Pan Y. Shear bond testing of concrete repairs. Cement and Concrete Research, 29 (7), 1999, pp. 1067-1076.

[3] Bentz DP, De la Varga I, Muñoz JF, Spragg RP, Graybeal BA, S.Hussey DS, Jacobson DL, Jones SZ, LaManna JM. Influence of Substrate Moisture State and Roughness on Interface Microstructure and Bond Strength: Slant Shear vs. Pull-Off Testing. Cement and Concrete Composites, 87, 2018, pp. 63-72.

[4] Berto F, Sandnes L. Computational Advantages of the Local Strain Energy Density for Fracture and Fatigue Design IOP Conf. Ser.: Materials Science Engineering 416, 2018012060.

[5] Beushausen H. Long-Term Performances of Bonded Overlays Subjected to Differential Shrinkage. PhD Thesis, University of Cape Town, South Africa, 2005, pp. 1-264.

[6] Beushausen H. The influence of concrete substrate preparation on overlay bond strength. Magazine of Concrete Research 62 (11), 2010, pp. 845-852.

[7] Beushausen H, Höhlig B, Talotti M. The influence of substrate moisture preparation on bond strength of concrete overlays and the microstructure of the OTZ. Cement and Concrete Research 92, 2017, pp.84-91. 
[8] Bissonnette B, Courard L, Garbacz A, Vaysburd AM, Von Fay KF, Robertson B. Development of specifications and performance criteria for surface preparation based on issues related to bond strength. Final Report ST-2017-2886-1, U.S. Department of the Interior, 2017, pp. 1-198.

[9] Bissonnette B, Vaysburd AM, Von Fay KF. Moisture Content Requirements for Repair, Part 1: Concrete Repair Testing. Report Number MERL-2013-63, U.S. Department of the Interior, 2014, pp. 1-45.

[10] Bonaldo E, Barros JAO, Lourenço PB. Bond characterization between concrete substrate and repairing SFRC using pull-off testing. International Journal of Adhesion and Adhesives 25 (6), 2005, pp. 463-474.

[11] Branco FA, da Silva VD, Júlio ENBS. Concrete-to-concrete bond strength: Influence of an epoxy-based bonding agent on a roughened substrate surface. Magazine of Concrete Research 57 (8), 2005, pp. 463-468.

[12] Brühwiler E. Ajouter de la plus-value aux ouvrages existants. Proceedings of the "Journée GUMA 2019".

[13] Brühwiler E, Denarié E. Rehabilitation of concrete structures using Ultra-High Performance Fibre Reinforced Concrete. The Second International Symposium on Ultra High Performance Concrete. March 05-07, 2008, Kassel, Germany.

[14] Castiglioni CA, Kanyilmaz A, John B. Simplified numerical modeling of elevated silos for nonlinear dynamic analysis. International Journal of Earthquake Engineering, XXXIII (1-2), CTA 2015.

[15] ChunPing G, Guang Y, Wei S. Ultrahigh performance concreteproperties, applications and perspectives. Science China Technological Sciences 58 (4), 2015, pp. 587-599.

[16] Delatte NJ, Wade DM, Fowler DW. Laboratory and Field Testing of Concrete Bond Development for Expedited Bonded Concrete Overlays. ACI Materials Journal, 2000.

[17] Delatte NJ, Williamson MS, Fowler DW. Bond strength development with maturity of high-early-strength bonded concrete overlays. ACI Materials Journal 97 (2), 2000, pp. 201-207. 
[18] Espeche AD, León J. Estimation of bond strength envelopes for old-tonew concrete interfaces based on a cylinder splitting test. Construction and Building Materials 25(3), 2011, pp. 1222-1235.

[19] Falope FO, Lanzoni L, Tarantino AM. Double lap shear test on steel fabric reinforced cementitious matrix (SFRCM). Composite Structures 201 (2018) 503-513.

[20] Falope FO, Lanzoni L, Tarantino AM. Modified hinged beam test on steel fabric reinforced cementitious matrix (SFRCM). Composites Part B 146, 2018, ,pp. 232-243.

[21] Farzad M, Shafieifar M, Azizinamini A. Experimental and numerical study on bond strength between conventional concrete and Ultra HighPerformance Concrete (UHPC). Engineering Structures 186, 2019, pp. 297-305.

[22] Gaspari GM, Zanoli O, Pescara M. Three-dimensional Modelling of the Tunnel Intersections In Weak Rock Mass On the Kadikoy-Kartal Metro Line of Istanbul. International Society for Rock Mechanics and Rock Engineering, 2010.

[23] Granju JL. Debonding of thin cement-based overlays. Journal of Materials in Civil Engineering 13 (2), 2001, pp. 114-120.

[24] Granju JL, Sabathier V, Turatsinze A, Toumi Interface between an old concrete and a bonded overlay: debonding mechanism. Interface Science 12 (4), 2004, pp. 381-388

[25] Guingot L, Dekhil D, Soulier P. Strenghtening of hydraulic structures with uhpc. RIELM-fib-AFGC Int. Symposium on Ultra-High Performance Fibre-Reinforced Concrete, UHPFRC 2013 - October 1-3, 2013, Marseille, France.

[26] Gumeni K, Kaçani J, Koça O. Crack problems in the metallic steel structure and the use of computing methods for the definition of the stress state in the cracks area. Aktet, 4, 2, 2011.

[27] Hajar Z, Novarin M, Servant C, Grégory Généreux, Davy Przybla, Daniel Bitar. Innovative solution for strengthening orthotropic decks using UHPFRC: The Illzach bridge. RILEM-fib-AFGC Int. Symposium on 
Ultra-High Performance Fiber-Reinforced Concrete, UHPFRC 2013 - October 1-3, 2013, Marseille, France.

[28] Hamdy KSE, Heba AM, Mahmoud K, Sayed A. Mechanical Properties of Ultra-High Performance Fiber Reinforced Concrete. International Journal of Engineering and Innovative Technology 4 (4), 2014, pp. 4-10.

[29] Harris DK, Muøoz MAC, Gheitasi A, Ahlborn TM, Rush SV. The challenges related to interface bond characterization of ultra-high-performance concrete with implications for bridge rehabilitation practices. Advanced Civil Engineering Materials 4(2), 2014, pp.75-101.

[30] Hussein HH, Walsh KK, Sargand SM, Al Rikabi FT, Steinberg EP . Modeling the Shear Connection in Adjacent Box-Beam Bridges with Ultra-High Performance Concrete Joints - Part I: Model Calibration and Validation. Journal of Bridge Engineering 22(8), 2017.

[31] Júlio ENBS, Branco FAB, Silva VD, Lourenço JF. Influence of added concrete compressive strength on adhesion to an existing concrete substrate. Building and Environment 41(12), 2006, pp.1934-1939.

[32] Krtulovic-Opara N, Toutanj H. Infrastructural repair and retrofit with HPFRCCs. Paper presented at the proceeding of the Second International RILEM Workshop High Performance Fibre Reinforced Cement Composites 2, Ann Arbor, USA, June 11-14-1995.

[33] Lampropoulos A, Paschalis SA, Tsioulou O, Dritsos SE. Strengthening of reinforced concrete beams using ultra high performance fibre reinforced concrete (UHPFRC). Engineering Structures 106, 2016, pp. 370-384.

[34] Lanzoni L, Nobili A, Tarantino AM. Performance evaluation of a polypropylene-based draw-wired fibre for concrete structures. Construct. Build. Mater. 28 (2012) 798-806.

[35] Lanzoni L, Radi E. A loaded Timoshenko beam bonded to an elastic half plane. International Journal of Solids and Structures 92-93 (2016), pp. 76-90.

[36] Lanzoni L, Tarantino AM. Damaged hyperelastic membranes. Int. J. NonLinear Mech. 60 (2014) 9-22. 
[37] Lanzoni L, Tarantino AM. Equilibrium configurations and stability of a damaged body under uniaxial tractions. ZAMP Zeitsc. Angew. Math. Phys. 66(1) (2015) 171-190.

[38] Lanzoni L, Tarantino AM. A simple nonlinear model to simulate the localized necking and neck propagation. Int. J. NonLinear Mech. 84 (2016) 94-104.

[39] Logan A, Choi W, Mirmiran A, Rizkalla S, Zia P. Short-term mechanical properties of high-strength concrete. ACI Materials Journal 106 (5), 2009, pp. 413-418.

[40] Luković M, Ye G. Effect of moisture exchange on interface formation in the repair system studied by $x$-ray absorption. Materials 9 (2), 2016, pp. $1-17$.

[41] Mavar K, Skazlic M. Influence of construction technology on the adhesion of remedial concrete. Gradevinar (Journal of the Croatian Association of Civil Engineers) 64, 2012, pp. 545-552.

[42] Noshiravani T, Brühwiler E. Experimental investigation on reinforced ultra-highperformance fiber-reinforced concrete composite beams subjected to combined bending and shear. ACI Structural Journal 110(2), 2013, pp. 251-262.

[43] Ono T. Application of ultra-high-strength fiber-reinforced concrete for irrigation channel repair works. In: Toutlemonde F, Resplendino J, eds. Designing and building with UHPFRC- State of the Art and Development, 2011, pp. 541-552.

[44] Rikards R, Buchhoiz FG, Bledzki AK, Wacker G, Korjakin A. Mode I, mode II, and mixed-mode I/II interlaminar fracture toughness of GFRP influenced by fiber surface treatment. Mechanics of Composite Materials 32 (5) , 1996, pp. 439-462.

[45] Safdar M, Matsumoto T, Kakuma K. Flexural behavior of reinforced concrete beams repaired with ultra-high performance fiber reinforced concrete (UHPFRC). Composite Structures 157, 2016, pp.448-460.

[46] Sandmann J, Poeppinghaus H. Tensile loads membrane constructions without cutting patterns-computer based modeling and analysis of high 
points. VII International Conference on Textile Composites and Inflatable Structures, Structural membranes 2015.

[47] Santos P, Joumal EJ. Factors affecting bond between new and old concrete. ACI Materials 85(2), 2011, pp.117-125.

[48] Savino V, Lanzoni L, Tarantino AM, Viviani M. Tensile constitutive behavior of high and ultra-high performance fibre-reinforced concretes. Construction and Building Materials 186, 2018, pp. 525-536.

[49] Savino V, Lanzoni L, Tarantino AM, Viviani M. Simple and effective models to predict the compressive and tensile strength of HPFRC as the steel fiber content and type changes. Composites Part B 137, 2018, pp. 153-162.

[50] Savino V, Lanzoni L, Tarantino AM, Viviani M. An extended model to predict the compressive, tensile and flexural strengths of HPFRCs and UHPFRCs: Definition and experimental validation. Composites Part B 163, 2019, pp. 681-689.

[51] Silfwerbrand J. Shear bond strength in repaired concrete structures. Materials and Structures 36 (6), 2003, pp. 419-424.

[52] Silfwerbrand J, Beushausen H, Courard L. Bond. In: Bissonnette B, Courard L, Fowler DW, Granju JL, eds. Bonded Cement-Based Material Overlays for the Repair, the Lining or the Strengthening of Slabs or Pavements, RILEM State-of-the-Art Report Technical Committee 193-RLS. 2011, pp. 51-79.

[53] Tarantino AM. Equilibrium paths of a hyperelastic body under progressive damage. Journal of Elasticity, 114, 2014, pp. 225-250.

[54] Tayeh BA, Bakar BA, Johari MM, Voo YL. Mechanical and permeability properties of the interface between normal concrete substrate and ultra high performance fiber concrete overlay. Construction and Building Materials 36, 2012,pp.538-548.

[55] Using Strand\%. G+D Computing, 1999.

[56] De la Varga I, Muñoz JF, Bentz DP, Graybeal BA. Effect of the interface moisture content on the bond performance between a concrete substrate 
and a non-shrink cement-based grout. 2015 National Accelerated Bridge Construction Conference, Miami, FL, 2015.

[57] Vaysburd AM, Bissonnette B, Thomassin MM, Von Fay KF, Harrell SJ, Robertson B. Concrete substrate moisture requirements for effective concrete repairs. Report ST-2016-2886-01, 2016, pp. 1-65.

[58] Xie HC, Li GY, Xiong GJ. Microstructure model of the interfacial zone between fresh and old concrete. Jorunal of Wuhan University of Technology-Mater Sci Ed 17(4), 2002, pp. 64-68.

[59] Yin H, Teo W, Shirai K. Experimental investigation on the behaviour of reinforced concrete slabs strengthened with ultra-high performance concrete. Construction and Building Materials 155, 2017, pp. 463-474.

[60] Yin H, Shirai K, Teo W. Numerical model for predicting the structural response of composite $U H P C$-concrete members considering the bond strength at the interface. Composite Structures 215, 2019, pp. 185-197.

[61] Standard test method for tensile strength of concrete surfaces and the bond strength or tensile strength of concrete repair and overlay materials by direct tension (pull-off method). ASTM C1583, 2013.

[62] Standard test method for bond strength of epoxy-resin systems used with concrete by slant shear. ASTM C882-a, 2013.

[63] EN 13412. Products and systems for the protection and repair of concrete structures - Determination of modulus of elasticity in compression. 2006.

[64] EN 12390-3. Testing hardened concrete - compressive strength of test specimens. 2003.

[65] SN EN 505262 Construction en béton. 2013. 


\section{List of Figures}

$1 \quad$ Switzerland 2018 [12] - Retrofitting of a bridge deck member by using a commercial UHPFRC . . . . . . . . . . . . 3

2 Illustration reported in [23] of a cracking/debonding path along the interface due to loading conditions on concrete pavements

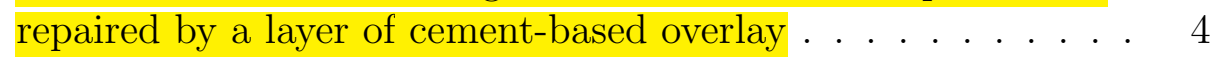

3 Roughness profile scanned for a given series (measuring in meters $\ldots \ldots \ldots \ldots \ldots \ldots \ldots$

4 Bond test configuration designed by authors: (1) substrate, (2) overlay, (3) interface, (4) slip point measured by LDTV, (5) bearing plates, (6) loading device, (7) force transducer, (8)

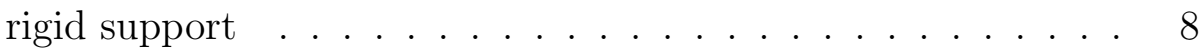

5 a) Interface profile observed by cutting the retrofitted member; b) Modeling of the interface between the substrate (MIR) (1) and the overlay (1-mm mesh) (5). The contact-condition effect between the two materials is modeled by using master-slave elements (2). The peeling-opening (mode I) and the shear-slip (mode II) relationships at the interface are modeled by using $100 \mu \mathrm{m}$-vertical (3) and $1000 \mu \mathrm{m}$-horizontal (4) truss elements, respectively

$6 \quad$ Strand7 environment. Series NH-dry: The function stress vs strain permits to construct the nonlinear cohesive law governing the interface response subjected to normal (a) and shear (b) stresses. In each figure, the points in which the slope of the function stress vs strain changes are labeled according to letter a, b, c, etc. . . . . . . . . . . . . . 13

$7 \quad$ FE simulation of the cracking/debonding pattern of series NH-

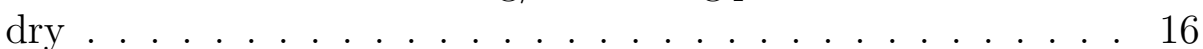

8 Analysis of the stress field on the modeled interface in series NH-dry recorded by the nonlinear static analysis: a) normal stress (mode I), b) shear stress (mode II). Load vs slip/debonding curve: c) simulation and experiment . . . . . . . . . . . 17

9 Numerical and experimental results of the model considering different conditions of type of overlay and moisture conditioning of the surface substrate prior to the application of the

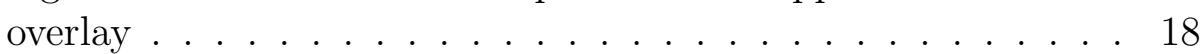


10 Surface failure observed after cracking/debonding of a) NHdry, b) NH-75, c) NH-SSD, d) NU-dry, e) NU-75, f) NU-SSD . 19 